\title{
Fighting cytomegalovirus-caused diseases: the immunologic approach
}

\author{
H. W. Doerr ${ }^{1}$
}

Published online: 22 August 2016

(C) Springer-Verlag Berlin Heidelberg 2016

The infection with human cytomegalovirus (HCMV) is spread worldwide and mostly harmless for immunocompetent individuals. However, it is threatening for individuals whose immune system is still immature (e.g. newborns), immunocompromised (e.g. AIDS or tumour patients) or physiologically or therapeutically immunosuppressed (e.g. pregnancy, patients with organ transplantation). The CMV infection, once acquired, gets persistent as proviral latent infection or as low-level chronic infection. Fighting CMV infection or reactivation has focused on rapid viral diagnosis, antiviral therapy and careful monitoring. However, throughout the whole microbiology, chemotherapy is increasingly restricted by development of resistances. Thus, fighting infectious diseases, the immunologic approach is of increasing relevance. Last year, this journal has launched two special issues on this topic $[1,2]$. Concerning research on CMV and other persistent infections, two previous special issues have been continued $[3,4]$.

HCMV infection does not provide immunity against reinfection and recurrence. The virus dissemination and transmission is also cell-associated. Leucocyte depletion eliminates CMV infectivity of blood donations. Thus, the development of active or passive immunization against HCMV is difficult and was only partly promising up to date, as far as classical methods were used [5]. Nevertheless, the advent of vaccination against herpes zoster

H. W. Doerr

H.W.Doerr@em.uni-frankfurt.de

1 Institute of Medical Virology, Goethe University Hospital, Paul-Ehrlich-Str. 40, 60596 Frankfurt am Main, Germany is an encouraging example despite some concerns [6]. Similar to HIV, an HCMV vaccine must be superior to wild virus in inducing immunity and must stimulate the cell-mediated as well as the humoral immune responses. Cell-mediated immune response is HLA-restricted. This makes the therapeutic intervention difficult, although the adoptive transfer of $\mathrm{T}$ cells against HCMV has proved successful.

In two papers in this issue, the virologists of the University of Mainz, internationally leading CMV specialists, review new approaches to the immunotherapeutic control of CMV diseases. N.A.W. Lemmermann and M.J. Reddehase outline a novel mouse model with "humanized" antigen presentation as a new preclinical study tool. Antigenically chimeric CMV and HLA-transgenic mice will contribute to test the antiviral function of human-specific $\mathrm{T}$ cells and analyse the immunologic network in vivo. A test model was missing, since human and animal CMVs are strictly host species-specific.

B. Plachter reviews the progress and setbacks in creating a vaccine to prevent the congenital CMV disease frequently seen in developing countries and still being threatening in the better developed world. Modern molecular methods have opened the way to identify crucial antigenic epitopes on the virus for a stronger induction of humoral and cellular immune responses. So, the HCMV vaccine development becomes more promising.

\section{References}

1. Roggendorf M, Gerlich W (eds) (2015) Therapeutic vaccination in chronic hepatitis B-approaches, problems, and new perspectives. Med Microbiol Immunol 204(1) (special issue)

2. Reddehase MJ (ed) (2015) Cytomegalovirus. Med Microbiol Immunol 204(3) (special issue) 
3. Bhakdi S (ed) (2012) Mechanisms of infection and persistence of infectious agents. Med Microbiol Immunol 201(4) (special issue)

4. Reddehase MJ (ed) (2008) Cytomegalovirus. Med Microbiol Immunol 197(2) (special issue)
5. Doerr HW, Berger A (2014) Vaccination against infectious diseases: what is promising? Med Microbiol Immunol 203(6):365-371

6. Doerr HW (2013) Progress in VZV vaccination? Some concerns. Med Microbiol Immunol 202(4):257-258 